\section{Cureus}

Received 10/07/2013

Review began 10/07/2013

Published 10/21/2013

\section{Copyright 2013}

Nussbaum et al. This is an open access article distributed under the terms of the Creative Commons Attribution License CC-BY 3.0., which permits unrestricted use, distribution, and reproduction in any medium, provided the original author and source are credited.

\title{
Atypical and Malignant Meningiomas: Increasing Incidence?
}

\author{
Eric S. Nussbaum ${ }^{1}$, Archie Defillo ${ }^{2}$, Leslie A. Nussbaum ${ }^{3}$ \\ 1. John Nasseff Neuroscience Institute, MN Neurovascular \& Skull Base Surgery, National Brain \\ Aneurysm Center at the John Nasseff Neuroscience Institute, MN Neurovascular \& Skull Base Surgery 2. \\ Centracare Hospital 3. Midwest Brain Tumor Center, John Nasseff Neuroscience Institute
}

$\square$ Corresponding author: Eric S. Nussbaum, lnussbaum@comcast.net

Disclosures can be found in Additional Information at the end of the article

\section{Abstract}

Introduction: Traditionally, the vast majority of meningiomas have been benign lesions with a low propensity for regrowth or spread following gross total removal. Over the past five years, our center has encountered a sharp increase in the percentage of meningiomas with pathological evidence of atypical or malignant features. This report addresses our growing experience with this entity.

Methods: We retrospectively reviewed records of all patients evaluated for a meningioma at our center from 2002-2009. Patients followed with serial imaging studies or treated presumptively with radiosurgery without pathological diagnosis were excluded from review.

Results: Over an eight year period, we encountered 382 patients with a presumptive diagnosis of meningioma and operated on 187. Of these, 18 (9.6\%) had atypical or malignant features on pathological evaluation. In this group, five had previously undergone cranial irradiation (three for childhood leukemia); the remainder had no obvious predisposing factors. Six involved the skull base; the remainder were convexity or parasagittal. Despite aggressive resection, all lesions recurred and required additional surgery and adjuvant radiotherapy and/or chemotherapy.

Conclusions: Based on our experience, it is possible that the incidence of atypical/malignant meningiomas is increasing. This may be due to a growing population of childhood cancer survivors, though most patients had no obvious predisposing factors. The referral nature of our practice may have contributed to our encountering more complex lesions; but other than local edema, these lesions did not demonstrate unusual features suggesting malignancy on preoperative imaging. In our experience, meningiomas no longer represents a uniformly benign disorder. This information may be important when counseling patients regarding prognosis, particularly before a pathological diagnosis has been made.

Categories: Radiation Oncology, Neurosurgery, Oncology

Keywords: brain tumor, malignant, meningioma

\section{Introduction}

Meningiomas have traditionally been considered benign tumors. Many lesions are followed with serial imaging without biopsy or resection because of their presumed benign natural history. In addition, most neurosurgeons are trained to tell their patients that these lesions are "almost always" benign when addressing issues of prognosis, particularly in the preoperative 
period. Over the past five years, we have encountered a steady increase in the percentage of atypical or malignant meningiomas seen in our subspecialized brain tumor practice. This study was undertaken to better understand the exact percentages of Grade II and Grade III lesions seen within our practice.

\section{Materials And Methods}

We retrospectively reviewed records of all patients evaluated for a meningioma at our tertiary referral center from 2002-2009. Based at a private hospital, our center represents a multidisciplinary brain tumor program, which includes subspecialized neurosurgery, radiation medicine, and neuro-oncology. Patients followed with serial imaging studies or treated presumptively with radiosurgery without pathological diagnosis were excluded from review. Only patients with a formal pathological report available for review were included in the study. Reports of imaging studies, pathology reports, operative notes, and outpatient clinic records were reviewed in all cases. Pathological grading was evaluated based on the 2007 WHO guidelines [1].

\section{Results}

Over an eight year period, we encountered 382 patients with a presumptive diagnosis of meningioma and operated on 187. Of these, 18 (9.6\%) had atypical or malignant features on pathological evaluation. In this group, five had previously undergone cranial irradiation (three for childhood leukemia); the remainder had no obvious predisposing factors. Six involved the skull base; the remainders were convexity or parasagittal. Despite aggressive resection, all lesions recurred and required additional surgery as well as adjuvant radiotherapy and/or chemotherapy.

\section{Discussion}

Based upon morphologic criteria, the World Health Organization (WHO) divides meningiomas into three groups. Grade I meningiomas are lesions considered to have a low risk of recurrence, and non-aggressive re-growth. More severely, Grade II (atypical, clear cell, chordoid) and Grade III (rhabdoid, papillary, anaplastic) are lesions with a greater risk of recurrence and aggressive behavior. Grade II and III lesions characteristically have a higher cell proliferative index and a tendency of brain invasion [1-2]. Histologically, there is an increase in cellularity of small cells with a profound increment of mitotic activity, which is characterized by a high nuclear/cytoplasm ratio, prominent nucleoli, uninterrupted patternless growth/sheet-like growth, and foci of spontaneous necrosis. Mitotic activity is more pronounced with Grade III lesions, occasionally resembling a carcinoma, sarcoma, or melanoma [3].

Previous studies have demonstrated an association between radiation and subsequent development of meningiomas [4-5]. In our series, five patients (1.31\%) had a clinical history of previous radiation exposure; three of those patients (60\%) underwent irradiation due to childhood leukemia. Aggressive meningiomas seem to be significantly higher in our series, with $9.6 \%$ of patients having atypical or malignant features on pathological evaluation. Seventeen of 18 treated patients (94\%) had Grade II lesions, and a single case (6\%) was reported as a Grade III meningioma. Six lesions involved the skull base; the remainder were convexity or parasagittal lesions. Despite aggressive resection, all tumors recurred, requiring additional surgery and adjuvant radiotherapy and/or chemotherapy.

We are aware that our study has several limitations, including the fact that it represents a retrospective chart review. We suspect that the increasing incidence of more aggressive meningiomas may be related to a growing number of childhood cancer survivors seen in our practice, though the majority of patients in our cohort had no obvious predisposing factors. 
More importantly, the current WHO 2007 grading system represented a significant change from the 1993 version. More objective and reproducible definitions of Grade II and III meningiomas may be resulting in a grading shift with increasing numbers of patients re-graded as WHO II tumors [6]. Along these lines, more recent comparative studies that have utilized the WHO criteria published in 2007 have shown a significant increase in the incidence of Grade II meningiomas, rising from a range of $5-7 \%$ to a range as high as $20-38 \%$ [7-8].

\section{Conclusions}

Based on our experience, it is possible that the incidence of atypical/malignant meningiomas is increasing. This may be due to a growing population of childhood cancer survivors, though most patients had no obvious predisposing factors. The referral nature of our practice may have contributed to our encountering more complex lesions; but other than local edema, these lesions did not demonstrate unusual features suggesting malignancy on preoperative imaging. In our experience, meningiomas no longer represent a uniformly benign disorder. This information may be important when counseling patients regarding prognosis, particularly before a pathological diagnosis has been made.

\section{Additional Information}

\section{Disclosures}

Human subjects: Consent was obtained by all participants in this study. N/A issued approval N/A. All data was obtained from retrospective chart reviews and did not require review by an Ethics Committee or a protocol number. Animal subjects: All authors have confirmed that this study did not involve animal subjects or tissue. Conflicts of interest: In compliance with the ICMJE uniform disclosure form, all authors declare the following: Payment/services info: All authors have declared that no financial support was received from any organization for the submitted work. Financial relationships: All authors have declared that they have no financial relationships at present or within the previous three years with any organizations that might have an interest in the submitted work. Other relationships: All authors have declared that there are no other relationships or activities that could appear to have influenced the submitted work.

\section{References}

1. Perry A, Louis DN, Scheithauer BW, et, al.: Meningiomas. WHO Classification of Tumours of the Central Nervous System. Louis, DN, Ohgaki, H, Wiestler, OD, Cavenee, WK (ed): IARC Press, Lyon; 2007. 164.

2. Wiemels J, Wrensch M, Claus EB: Epidemiology and etiology of meningioma . J Neurooncol. 2010, 99:307-314. 10.1007/s11060-010-0386-3

3. Whittle IR, Smith C, Navoo P, Collie D: Meningiomas. The Lancet. 2004, 363:1535-1543.

4. Taylor AJ, Little MP, Winter DL, Sugden E, Ellison DW, Stiller CA, Stovall M, Frobisher C, Lancashire ER, Reulen RC, Hawkins MM: Population-based risks of CNS tumors in survivors of childhood cancer: The British Childhood Cancer Survivor Study. J Clin Oncol. 2010, 28:52875293. 10.1200/JCO.2009.27.0090

5. Banerjee J, PääkköE, Harila M, Herva R, Tuominen J, Koivula A, Lanning M, Harila-Saari A: Radiation-induced meningiomas: A shadow in the success story of childhood leukemia . Neuro Oncol. 2009, 11:543-549. 10.1215/15228517-2008-122

6. Combs SE, Schulz-Ertner D, Debus J, von Deimling A, Hartmann C: Improved correlation of the neuropathologic classification according to adapted world health organization classification and outcome after radiotherapy in patients with atypical and anaplastic meningiomas. Int J Radiat Oncol Biol Phys. 2011, 81:1415-1421. 10.1016/j.ijrobp.2010.07.039

7. Yang SY, Park CK, Park SH, Kim DG, Chung YS, Jung HW: Atypical and anaplastic meningiomas: Prognostic implications of clinicopathological features. J Neurol Neurosurg Psychiatry. 2008, 79:574-580. 


\section{Cureus}

8. Perry A, Scheithauer BW, Stafford SL, Lohse CM, Wollan PC: "Malignancy" in meningiomas: A clinicopathologic study of 116 patients, with grading implications. Cancer. 1999, 85:20462056. 